\section{Aspectos da satisfação das mulheres com a assistência ao parto: contribuição para o debate}

\author{
Aspects of women's satisfaction with childbirth \\ care in a maternity hospital in Rio de Janeiro
}

\author{
${ }^{1}$ Secretaria Municipal \\ de Saúde do Rio de Janeiro, \\ Rio de Janeiro, Brasil. \\ 2 Departamento de Endemias \\ Samuel Pessoa, Escola \\ Nacional de Saúde Pública, \\ Fundação Oswaldo Cruz, \\ Rio de Janeiro, Brasil. \\ 3 Departamento de \\ Epidemiologia e Métodos \\ Quantitativos em Saúde, \\ Escola Nacional de Saúde \\ Pública, Fundação Oswaldo \\ Cruz, Rio de Janeiro, Brasil. \\ Correspondência \\ Rosa Maria Soares \\ Madeira Domingues \\ Rua Afonso Cavalcanti 455 \\ sala 809, Rio de Janeiro, $R J$ \\ 20211-901, Brasil. \\ rdomingues@pcrj.rj.gov.br
}

\begin{abstract}
The objective of this study was to evaluate factors associated with women's satisfaction with vaginal delivery at the Leila Diniz Maternity Hospital in Rio de Janeiro, Brazil. A cross-sectional study was conducted from March 1 to 30, 1999, using interviews with women who had undergone vaginal delivery. In order to analyze women's satisfaction, the following were used: (a) a scale to evaluate overall satisfaction with the birthing process; (b) description of the woman's reasons for this evaluation; and (c) analysis of factors associated with the evaluation of childbirth satisfaction. Chi-square for trend with a 5\% significance level was used to analyze the results. The results of the study showed high satisfaction with childbirth care (67\%), determined mainly by short labor time, good treatment by staff, low level of distress, absence of complications for the mother and baby, and presence of a family companion. The study also verified the association between women's satisfaction with information received during perinatal care and positive perceptions of the professionals responsible for providing care.
\end{abstract}

Perinatal Care; Humanizing Delivery; Patient Satisfaction
Rosa Maria Soares Madeira Domingues 1 Elizabeth Moreira dos Santos 2 Maria do Carmo Leal 3

\section{Introdução}

Gravidez e parto são eventos marcantes na vida das mulheres e de suas famílias. Representam mais do que simples eventos biológicos, já que são integrantes da importante transição do status de "mulher" para o de "mãe". Embora a fisiologia do parto seja a mesma, em nenhuma sociedade ele é tratado de forma apenas fisiológica, pois é um evento biossocial 1, cercado de valores culturais, sociais, emocionais e afetivos.

Vigora no Brasil um modelo de atenção ao parto em que este é definido como um evento médico, carregado de risco potencial. Nesse modelo, denominado médico ou tecnológico, a gestante é tratada como paciente, os partos ocorrem, em sua maioria, em ambiente hospitalar, sendo o médico o profissional responsável pela assistência, com utilização intensiva de intervenções obstétricas. Essa visão médica abstrai a gravidez do restante da experiência de vida da mulher, tratando-a como episódio médico isolado 2. Os significados que as mulheres atribuem às experiências de gravidez e nascimento são ignorados e seus sentimentos e sua satisfação com o cuidado são considerados menos importantes do que sua segurança e a de seu bebê 2,3 .

Ao longo das últimas décadas, tem-se observado um movimento crescente de críticas ao modelo brasileiro de assistência ao parto e aos seus resultados, endossado mais recente- 
mente pelo próprio Ministério da Saúde 4 . Esse movimento, denominado "humanização da assistência ao parto e ao nascimento", surge em vários serviços que buscam a implantação de uma atenção menos intervencionista, baseada em uma participação ativa da mulher no processo, com maior ênfase nos aspectos sociais e emocionais da parturição, incorporando a possibilidade de presença de acompanhante familiar na rotina de assistência ao parto.

Apesar dessas experiências e dos bons resultados perinatais relatados 5,6, a produção nacional relativa aos modelos de atenção ao parto é ainda modesta, e existem poucos trabalhos científicos que avaliem a implantação dessas práticas 7 e a percepção dos usuários em relação às mesmas 8,9.

$\mathrm{Na}$ literatura internacional, verifica-se a existência de trabalhos que têm avaliado e criticado as práticas obstétricas $3,10,11,12$, contribuindo para a implantação de modelos de atenção que privilegiem condutas reconhecidamente benéficas. Observam-se também estudos que abordam questões relacionadas à autonomia e à satisfação das mulheres durante a assistência à gestação e ao parto, mas que têm sido realizados em contextos sócio-culturais e assistenciais diversos do brasileiro, o que dificulta uma transposição de seus resultados para a nossa realidade.

A produção científica nacional necessita ser ampliada nessa área temática, contribuindo para a implantação de serviços de atenção ao parto menos intervencionistas, que atuem na perspectiva de propiciar a vivência do trabalho de parto, parto e nascimento como experiências positivas e enriquecedoras. É importante que esses estudos incluam unidades de saúde voltadas para o atendimento das mulheres de menor nível sócio-econômico, já que alguns profissionais de saúde resistem a mudanças no modelo assistencial, atribuindo os bons resultados obtidos em outros países às melhores condições de vida, de saúde e de "educação" das mulheres atendidas.

Uma pesquisa que estudou a prática do acompanhante familiar em uma maternidade pública da Secretaria Municipal de Saúde do Rio de Janeiro, com um projeto-piloto de humanização da assistência ao parto e ao nascimento, também aferiu o grau de satisfação das mulheres com a assistência. Acreditava-se que uma baixa satisfação com a assistência ao parto pudesse dificultar uma avaliação positiva da prática do acompanhante 13 .
O objetivo deste artigo é analisar os fatores associados à satisfação das mulheres com a atenção ao parto normal na maternidade em estudo, que presta assistência a uma clientela de baixa renda, residente em sua própria área de abrangência.

\section{Metodologia}

Trata-se de estudo com desenho transversal, conduzido mediante análise de entrevistas realizadas com puérperas de parto vaginal internadas na Maternidade Leila Diniz. Foi definido como universo do estudo o total de puérperas que apresentou parto vaginal de fetos pesando $500 \mathrm{~g}$ ou mais, na instituição, no período de lo a 30 de março de 1999. A escolha desse mês deveu-se ao fato de ser um período em que a maternidade apresenta funcionamento normal, sem a presença de fatores que pudessem interferir na sua dinâmica de atendimento, como feriados ou férias de um número elevado de profissionais. Através do Sistema de Informação sobre Nascidos Vivos (SINASC), foi possível estimar a realização de aproximadamente 250 entrevistas.

Foram entrevistadas 246 puérperas de parto vaginal, que correspondem a $97 \%$ do total de mulheres elegíveis para o estudo, considerando-se a exclusão das que apresentaram perdas fetais ou neonatais. Seis mulheres não foram entrevistadas porque receberam alta antes que a entrevista tivesse sido realizada, e uma se recusou a participar do estudo. Estas mulheres não diferiam daquelas que foram entrevistadas no que se refere à média de idade e número de partos, local de residência, ocupação e situação de saúde do recém-nato.

As puérperas foram identificadas no livro de registro de partos normais, instrumento utilizado regularmente pela instituição desde a sua inauguração, com cobertura de $100 \%$ dos partos.

As entrevistas foram realizadas por duas assistentes sociais do próprio serviço nas enfermarias de alojamento conjunto ou, excepcionalmente em caso de superlotação, no próprio centro obstétrico, no período mínimo de 24 horas após o parto, tentando-se, sempre que possível, garantir a privacidade da puérpera.

Utilizou-se um questionário fechado, contendo questões relacionadas às características sócio-demográficas, antecedentes obstétricos e da gestação atual, atendimento recebido na 
instituição durante a internação e perspectivas de modificação dos serviços de atenção ao parto.

Para avaliação da satisfação com a atenção ao parto, alguns cuidados foram adotados, como a utilização de uma questão com cinco opções de resposta, variando de "muito bom" a "muito ruim", o que, segundo Ware \& Hays 14, facilita a expressão de níveis de satisfação mais baixos, maior variabilidade nas respostas e maior associação com medidas de intenção de comportamento dos pacientes. A pergunta sobre a satisfação foi feita ao final de uma série de perguntas que verificavam aspectos diversos da assistência, o que também propicia a expressão de níveis mais baixos de satisfação, por permitir que o paciente reflita sobre aspectos específicos do contato com o serviço de saúde antes de avaliá-lo 14 . Uma última característica do instrumento a ser ressaltada foi a utilização de uma opção de resposta "outros", seguida de uma pergunta aberta, visando a permitir a expressão de opiniões e respostas não previstas.

Antes da realização de cada entrevista, foi feita uma abordagem individual às mulheres, com a apresentação dos objetivos da pesquisa e o convite para participar desta, sendo assinado um consentimento informado por cada pessoa entrevistada. Nesse momento, esclareceu-se também que não haveria registro do nome da puérpera no questionário a ser utilizado, a fim de impedir a sua identificação e garantir a confidencialidade das informações obtidas.

Para definirmos as variáveis que iriam aferir a avaliação da satisfação com a assistência ao parto, baseamo-nos em dois trabalhos que fizeram uma revisão da literatura científica a respeito do tema 15,16. Foram selecionadas seis variáveis independentes: (a) sentimentos em relação à gravidez atual, (b) expectativas em relação ao parto, (c) número de partos, (d) grau de informação em relação ao parto, (e) informação recebida durante o trabalho de parto e o parto; (f) relação com a equipe que prestou assistência.

Todos os questionários foram revisados pela pesquisadora principal, que também foi a responsável pela digitação dos mesmos. Para análise dos resultados, utilizou-se o teste estatístico do Qui-quadrado para teste de tendência, com nível de significância de 5\%. A satisfação das mulheres foi analisada agrupada em três categorias - "muito bom/bom", "nem bom, nem ruim" e "ruim/ muito ruim".

As falas e depoimentos registrados, quando considerados particularmente ilustrativos da percepção das mulheres em relação à questão que estava sendo investigada, serão apresenta- dos com o intuito de qualificar a análise dos resultados.

A amostra obtida de 246 mulheres foi adequada para o estudo da prática do acompanhante familiar, mas pequena para o estudo de algumas subcategorias das variáveis independentes que apresentaram prevalência muito baixa, considerando-se um erro de estimação de $10 \%$ e um grau de confiabilidade de $95 \% 17$.

\section{Resultados}

\section{Características sócio-demográficas,} obstétricas e da gestação atual

As mulheres entrevistadas tinham uma idade média de 24 anos, sendo $27,0 \%$ adolescentes (idade $<20$ anos) e aproximadamente $7,0 \%$ com idade superior a 35 anos. Um quarto das mulheres tinha quatro anos ou menos de instrução e $6,1 \%$ eram analfabetas. Apenas $1,6 \%$ apresentava nível superior de escolaridade. Eram naturais de outros estados $31,0 \%$ das mulheres, sendo a grande maioria $(75,0 \%)$ de estados do Nordeste. Mais de 90,0\% residiam em bairros da área denominada AP4, área de abrangência da Maternidade Leila Diniz. Mais de 80,0\% das mulheres eram unidas (casadas ou união consensual); 14,2\% eram mães solteiras dependentes de familiares e $4,5 \%$, mães solteiras chefes de família. Quase 52,0\% das mulheres se declararam pardas; $26,4 \%$, brancas, e $22,0 \%$, negras. A maioria das mulheres $(53,7 \%)$ referia ter tido trabalho remunerado nos últimos doze meses, sendo as principais ocupações a prestação de serviços (77,0\% destas domésticas), o comércio e atividades auxiliares (Tabela 1).

As mulheres entrevistadas tinham, em média, 2,7 gestações, num intervalo de 1 a 12 . Estavam na sua primeira gestação $32 \%$ delas e $25,6 \%$ apresentavam quatro ou mais gestações. Das mulheres que já haviam engravidado anteriormente, $32,9 \%$ tinham história de aborto. A média de partos era de 1,4 , e $35 \%$ das mulheres eram primíparas (Tabela 1 ).

A freqüência aos serviços de pré-natal foi alta (92\%), tendo sido referido que $95 \%$ da assistência prestada às gestantes ocorreu em unidades de saúde públicas ou conveniadas ao SUS. As gestantes apresentaram, em média, 6,2 consultas, e $41,2 \%$ não tiveram as seis consultas mínimas preconizadas pelo Ministério da Saúde. Apenas $11,0 \%$ das gestantes participaram de alguma atividade de grupo durante o pré-natal (Tabela 1). 
Satisfação das mulheres com

a atenção ao parto

Quase 70,0\% das mulheres avaliaram seu parto como "bom" ou "muito bom", e 16,7\% acharamno "ruim" ou "muito ruim". Na questão que verificava o porquê da opinião das mulheres sobre a parição, observamos que o sofrimento no parto, a má atenção da equipe, complicações do bebê e o parto demorado e/ou difícil surgiram como questões principais na percepção negativa do parto. Para as mulheres com percepção positiva, o parto rápido, o bom tratamento da equipe, o pouco sofrimento e o bom estado da mãe e do bebê foram os aspectos mais importantes (Tabela 2).

Outras questões positivas da parição também foram enfatizadas. O depoimento de uma delas revela a importância da experiência do parto para a sua vida:

"Foi uma experiência importante. Eu era uma pessoa muito seca. Depois do parto eu sinto que fiquei mais carinhosa, passei a dar mais valor ao lado emocional das pessoas" (25 anos, primeiro parto).

A presença do(a) acompanhante foi um fator que contribuiu para a satisfação com o trabalho de parto e o parto, sendo citado como razão da satisfação por 7,9\% do total de mulheres que avaliaram o parto como "muito bom/bom" (Tabela 2). Esse valor se eleva para $12,4 \%$ quando são selecionadas apenas as mulheres que tiveram acompanhante no trabalho de parto ou parto.

"O parto foi muito bom porque eu estava mais tranqüila, relaxada, por causa do pai que estava perto, me acalmando" (27 anos, terceiro parto). "O parto foi muito bom porque minha irmã me deu muita força e coragem na hora" (18 anos, segundo parto). "O parto foi lindo, muito bom, porque tive acompanhante e a equipe tratou bem. Sozinha não consegue, a dor é muito forte" (28 anos, primeiro parto).

Além de se descreverem as razões atribuídas pelas mulheres para uma maior ou menor satisfação com o parto, foram também estudadas algumas variáveis para verificar sua possível associação com essa satisfação (Tabelas 3 e 4).

A primeira delas foi o número de partos, sendo classificadas como primíparas as que estavam tendo seu primeiro parto por ocasião da pesquisa, e multíparas as que já haviam tido parto anteriormente.

Observamos uma maior satisfação com o parto entre as primíparas, porém essa diferença não foi significativa (Tabela 3). Entretanto, quando comparamos apenas o grupo que classificou o parto como muito bom, verificamos o
Tabela 1

Características sócio-demográficas, obstétricas e da gestação atual das puérperas entrevistadas. Maternidade Leila Diniz, Rio de Janeiro, Brasil, 1999.

\begin{tabular}{lcc}
\hline Características das puérperas & $\mathbf{n}$ & $\%$ \\
\hline Idade & 67 & 27,4 \\
$\quad<20$ anos & 181 & \\
Raça & & 73,6 \\
$\quad$ Parda/negra & 77 & 31,3 \\
Escolaridade & 200 & 81,3 \\
$\quad 0$ a 4 anos & 132 & 53,7 \\
Casada/Unida & 171 & 69,5 \\
Trabalho remunerado & 79 & 32,1 \\
Natural do Rio de Janeiro & 85 & 34,6 \\
Primigestas & 226 & 91,9 \\
Primíparas & 133 & 58,8 \\
Assistência pré-natal & 27 & 11,1 \\
Pré-natal com 6 ou + consultas* & & \\
Participação em grupo de gestantes & & \\
\hline
\end{tabular}

* Informação disponível para 226 puérperas que receberam assistência pré-natal. ** Informação disponível para 244 puérperas.

dobro de satisfação das primíparas em relação às multíparas $(30,6 \%$ x 14,9\%, p = 0,0061).

Em relação à segunda variável estudada, “sentimentos em relação à gravidez", verificamos que $34,6 \%$ das mulheres apresentaram apenas sentimentos negativos quando receberam o diagnóstico da gravidez, traduzidos por tristeza, desespero, pânico, desejo e/ou tentativa de interrupção da gestação. Foi verificada associação dos "sentimentos em relação à gravidez" com a satisfação no parto na faixa de avaliação "muito bom", observando-se um percentual duas vezes superior dessa avaliação entre as mulheres que não apresentavam sentimentos negati$\operatorname{vos}(24,8 \% \times 11,8 \%, p=0,0239)$. Não foi encontrada, contudo, associação dessa variável nas demais avaliações da satisfação (Tabela 3).

Para avaliar as expectativas das mulheres em relação ao parto, buscando identificar aquelas que estivessem mais apreensivas e pessimistas em relação à experiência da parição, foram escolhidas duas variáveis - "idéias sobre o parto" e "preocupação com o parto atual”.

As principais imagens citadas pelas mulheres quando pensavam no parto eram de dor/sofrimento $(48,0 \%)$, medo $(9,4 \%)$ ou outras idéias negativas $(4,3 \%)$. Em apenas $33,0 \%$ dos casos, as mulheres relatavam imagens positivas associadas à vida e à alegria do nascimento. Foi encontrada associação da variável "idéias sobre o parto" com a satisfação com o parto. Observamos que aproximadamente $40,0 \%$ das mulheres que apresentavam apenas idéias negativas 
Razões referidas pelas puérperas, segundo o grau de satisfação com a assistência ao parto. Maternidade Leila Diniz, Rio de Janeiro, Brasil, 1999.

\begin{tabular}{|c|c|c|c|c|c|c|}
\hline \multirow[t]{2}{*}{$\begin{array}{l}\text { Razões/grau de satisfação } \\
(n=246)\end{array}$} & \multicolumn{2}{|c|}{$\begin{array}{l}\text { Muito bom/bom } \\
\qquad(n=165)\end{array}$} & \multicolumn{2}{|c|}{$\begin{array}{c}\text { Nem bom, nem ruim } \\
(n=40)\end{array}$} & \multicolumn{2}{|c|}{$\begin{array}{l}\text { Muito ruim/ruim } \\
\qquad(\mathrm{n}=41)\end{array}$} \\
\hline & $\mathrm{n}$ & $\%$ & $\mathrm{n}$ & $\%$ & $\mathrm{n}$ & $\%$ \\
\hline Recém-nato bem & 36 & 21,8 & 10 & 25,0 & 0 & 0,0 \\
\hline Recém-nato c/ problemas & 0 & 0,0 & 0 & 0,0 & 3 & 7,3 \\
\hline Puérpera bem & 17 & 10,3 & 3 & 7,5 & 0 & 0,0 \\
\hline Puérpera c/ problemas & 0 & 0,0 & 3 & 7,5 & 0 & 0,0 \\
\hline Pouco sofrimento & 33 & 20,0 & 4 & 10,0 & 0 & 0,0 \\
\hline Muito sofrimento & 6 & 3,6 & 29 & 72,5 & 32 & 78,0 \\
\hline Equipe tratou bem & 36 & 21,8 & 2 & 5,0 & 0 & 0,0 \\
\hline Equipe tratou mal & 0 & 0,0 & 2 & 5,0 & 7 & 17,1 \\
\hline Parto rápido & 96 & 58,2 & 10 & 25,0 & 0 & 0,0 \\
\hline Parto demorado & 1 & 0,6 & 6 & 15,0 & 7 & 17,1 \\
\hline Aspectos positivos do parto & 6 & 3,6 & 3 & 7,5 & 0 & 0,0 \\
\hline Aspectos negativos do parto & 2 & 1,2 & 5 & 12,5 & 4 & 9,8 \\
\hline Presença de acompanhante & 13 & 7,9 & 1 & 2,5 & 0 & 0,0 \\
\hline Experiência de vida & 7 & 4,2 & 0 & 0,0 & 0 & 0,0 \\
\hline Outros aspectos positivos & 7 & 4,2 & 5 & 12,5 & 0 & 0,0 \\
\hline Outros aspectos negativos & 0 & 0,0 & 1 & 2,5 & 2 & 4,9 \\
\hline
\end{tabular}

Nota: Em cada faixa de satisfação, várias razões foram apresentadas pelas mulheres como justificativa para a satisfação referida, razão pela qual a soma é sempre superior a $100 \%$.

sobre o parto avaliaram-no como "nem bom, nem ruim", "ruim" e "muito ruim” (Tabela 3).

Não foi encontrada associação da variável "preocupação com o parto atual" com a satisfação com o parto, devendo-se ressaltar o elevado percentual de mulheres que apresentavam esse tipo de preocupação (sempre superior a 70,0\%) em todas as faixas de satisfação (Tabela 3). As preocupações estavam relacionadas principalmente às complicações de sua saúde e/ou do recém-nato $(47,4 \%)$, ao medo da morte $(20,0 \%)$, à dor do parto $(15,4 \%)$ e ao processo do parto em si (14,0\%).

Quanto à variável "grau de informação da gestante em relação ao parto”, verificamos que apenas $23,0 \%$ das mulheres sentiam-se completamente informadas sobre o que acontece com elas e com o bebê durante o parto, $43,0 \%$ não se consideravam informadas e $35,0 \%$ sentiam-se apenas parcialmente informadas. Menos da metade das gestantes $(44,0 \%)$ referiu ter recebido informações sobre o parto, sendo a principal fonte de informação a mãe e outros familiares (44,3\%). Apenas $17,7 \%$ das mulheres que freqüentaram serviço de pré-natal referiram esse serviço como fonte de informação. Observamos um maior percentual de gestantes sem informação entre aquelas que apresentaram menor satisfação com o parto, e maior per- centual de gestantes com informação completa entre aquelas que o avaliaram como "bom" ou "muito bom”. No entanto, essa diferença não apresentou significância estatística (Tabela 3).

A informação recebida durante a internação sobre diversos aspectos relacionados à assistência ao trabalho de parto e ao parto foi variável e, de modo geral, insuficiente. Apenas $60,0 \%$ das mulheres sentiram-se suficientemente informadas sobre a evolução do trabalho de parto e $63,0 \%$ sobre a saúde/bem-estar do bebê. Em relação aos exames realizados (toques vaginais, exames de sangue etc...), esse valor se reduz para $34,0 \%$, e as informações relacionadas aos medicamentos recebidos foram suficientes para apenas $30,0 \%$ das mulheres.

As informações recebidas pelas mulheres durante a assistência ao trabalho de parto e ao parto apresentaram uma clara associação com a satisfação com o parto. Com exceção da informação relativa à medicação recebida, as demais informações fornecidas à mulher - sobre a evolução do trabalho de parto, bem-estar do feto e exames realizados - apresentaram uma associação positiva com a satisfação com o parto. Ou seja, quanto mais completa ou suficiente a informação foi percebida pela mulher, maior a satisfação relatada com a assistência ao parto (Tabela 4 ). 
Variáveis relacionadas às características das puérperas, segundo grau de satisfação com o parto. Maternidade Leila Diniz, Rio de Janeiro, Brasil, 1999.

\begin{tabular}{|c|c|c|c|c|c|c|c|c|c|}
\hline \multirow[t]{2}{*}{ Variável/satisfação } & \multicolumn{2}{|c|}{ Muito bom/bom } & \multicolumn{2}{|c|}{ Nem bom, nem ruim } & \multicolumn{2}{|c|}{ Ruim/muito ruim } & \multicolumn{2}{|c|}{ Total } & \multirow[t]{2}{*}{ Valor de $p$} \\
\hline & $n$ & $\%$ & $\mathrm{n}$ & $\%$ & $\mathrm{n}$ & $\%$ & $n$ & $\%$ & \\
\hline \multicolumn{10}{|l|}{ Número de partos } \\
\hline Primípara & 61 & 71,8 & 11 & 12,9 & 13 & 15,3 & 85 & 100,0 & 0,4689 \\
\hline Multípara & 104 & $64,6 *$ & 29 & 18,0 & 28 & 17,4 & 161 & 100,0 & \\
\hline \multicolumn{10}{|c|}{ Sentimentos em relação à gestação } \\
\hline Apenas negativos & 53 & 62,4 & 17 & 20,0 & 15 & 17,6 & 85 & 100,0 & 0,3979 \\
\hline Positivos/outros** & 112 & $69,6^{\star \star \star}$ & 23 & 14,3 & 26 & 16,1 & 161 & 100,0 & \\
\hline \multicolumn{10}{|c|}{ 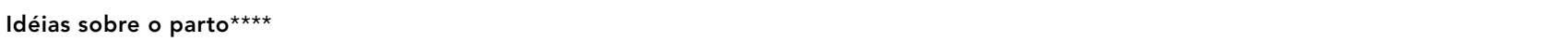 } \\
\hline Negativas & 88 & 60,3 & 30 & 20,5 & 28 & 19,2 & 146 & 100,0 & 0,0101 \\
\hline Positivas & 74 & 78,7 & 8 & 8,5 & 12 & 12,8 & 94 & 100,0 & \\
\hline \multicolumn{10}{|l|}{ Preocupação } \\
\hline Sim & 131 & 67,2 & 31 & 15,9 & 33 & 16,9 & 195 & 100,0 & 0,9348 \\
\hline Não & 34 & 66,7 & 9 & 17,6 & 8 & 15,7 & 51 & 100,0 & \\
\hline \multicolumn{10}{|c|}{ Informação sobre o parto } \\
\hline Não/parcial & 122 & 64,2 & 33 & 17,4 & 35 & 18,4 & 190 & 100,0 & 0,0814 \\
\hline Completa & 43 & 76,8 & 7 & 12,5 & 6 & 10,7 & 56 & 100,0 & \\
\hline
\end{tabular}

* Na análise apenas da faixa de satisfação "muito bom", primíparas 30,6\% x multíparas 14,9\% ( $p=0,0061)$.

** Inclui sentimentos positivos, ambivalentes, indiferentes e outros.

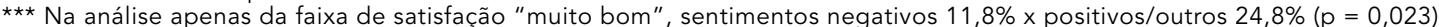

$\star \star \star \star$ Excluídas seis mulheres com idéias sobre o parto classificadas como "outras".

Nota: Para as subcategorias "primíparas", "sentimentos em relação à gestação - apenas negativos" e "informação sobre o parto

completa", o tamanho da amostra foi pequeno, considerando-se um erro de estimação de $10 \%$ e um grau de confiabilidade de $95 \%$.

A variável que verificava a percepção da mulher em relação à equipe que prestou assistência ao trabalho de parto e ao parto também apresentou associação com a satisfação. Mulheres que tiveram apenas opiniões positivas sobre a equipe que prestou assistência apresentaram maior satisfação com o parto (Tabela 4). Além dessa associação da satisfação com a percepção global positiva dos profissionais, duas opiniões específicas, "profissionais que forneceram pouca atenção" e "profissionais confusos", mostraram associação com uma menor satisfação com o parto $(\mathrm{p}<0,001$ para ambas opiniões). Das mulheres que consideraram os profissionais pouco atenciosos durante a assistência ao trabalho de parto e ao parto, $65,7 \%$ avaliaram o parto como "nem bom, nem ruim", "ruim" ou "muito ruim". Das mulheres que acharam os profissionais confusos, 75,0\% avaliaram o parto como "ruim" ou "muito ruim".

Vários depoimentos ilustram bem essa questão:

"O parto foi ruim porque o bebê nasceu na cama do pré-parto. A equipe poderia ter ajuda- do mais, poderia ter sido mais atenciosa" (18 anos, segundo parto). "Os médicos deram pouca atenção no pré-parto. Fiquei sozinha e ninguém vinha. Minha sugestão? Não deixar a mulher sozinha no pré-parto" (33 anos, quinto parto). "Me senti abandonada, eles sumiram (bebê nasceu na cadeira de rodas)" (19 anos, segundo parto). "Mais atenção dos médicos no pré-parto. Me senti jogada” (17 anos, segundo parto).

Algumas mulheres também se queixaram da forma agressiva com que foram tratadas:

"Os médicos gritaram comigo, não me ajudaram. As mulheres devem ser mais bem tratadas, eles deixam a mulher mais nervosa ain$d a$ " (22 anos, terceiro parto). "Forçaram muito a minha barriga, eu não estava agüentando mais. Na hora do parto foram estúpidos" (28 anos, segundo parto). "Os auxiliares de enfermagem me deixaram nervosa. Eram agressivos" (20 anos, segundo parto). "O médico não acreditou que o bebê ia nascer. Brigou comigo por causa da minha queixa. Os médicos devem ter maior paciência com as mulheres" (25 anos, quarto parto). 
Variáveis relacionadas à assistência ao parto, segundo o grau de satisfação relatado pelas puérperas.

Maternidade Leila Diniz, Rio de Janeiro, Brasil, 1999.

\begin{tabular}{|c|c|c|c|c|c|c|c|c|c|}
\hline \multirow[t]{2}{*}{ Variável/satisfação } & \multicolumn{2}{|c|}{ Muito bom/bom } & \multicolumn{2}{|c|}{ Nem bom, nem ruim } & \multicolumn{2}{|c|}{ Ruim/muito ruim } & \multicolumn{2}{|c|}{ Total } & \multirow[t]{2}{*}{ Valor de $\mathrm{p}$} \\
\hline & $\mathrm{n}$ & $\%$ & $\mathrm{n}$ & $\%$ & $n$ & $\%$ & $\mathrm{n}$ & $\%$ & \\
\hline \multicolumn{10}{|c|}{ Informação recebida durante a internação } \\
\hline \multicolumn{10}{|c|}{ a) Sobre evolução do trabalho de parto* } \\
\hline Insuficiente & 42 & 48,3 & 22 & 25,3 & 23 & 26,4 & 87 & 100,0 & \\
\hline Suficiente & 100 & 76,9 & 15 & 11,5 & 15 & 11,5 & 130 & 100,0 & $<0,0001$ \\
\hline \multicolumn{10}{|c|}{ b) Sobre bem-estar do feto* } \\
\hline Insuficiente & 41 & 50,0 & 16 & 19,5 & 25 & 30,5 & 82 & 100,0 & \\
\hline Suficiente & 102 & 74,5 & 22 & 16,1 & 13 & 9,5 & 137 & 100,0 & $<0,0001$ \\
\hline \multicolumn{10}{|c|}{ c) Sobre exames realizados* } \\
\hline Insuficiente & 85 & 55,9 & 32 & 21,1 & 35 & 23,0 & 152 & 100,0 & \\
\hline Suficiente & 65 & 84,4 & 6 & 7,8 & 6 & 7,8 & 77 & 100,0 & $<0,0001$ \\
\hline \multicolumn{10}{|c|}{ d) Sobre medicação recebida* } \\
\hline Insuficiente & 101 & 65,2 & 25 & 16,1 & 29 & 18,7 & 155 & 100,0 & \\
\hline Suficiente & 51 & 77,3 & 7 & 10,6 & 8 & 12,1 & 66 & 100,0 & 0,0968 \\
\hline \multicolumn{10}{|l|}{ Percepção da equipe } \\
\hline Negativa & 26 & 44,1 & 16 & 27,1 & 17 & 28,8 & 59 & 100,0 & \\
\hline Positiva & 139 & 74,3 & 24 & 12,8 & 24 & 12,8 & 187 & 100,0 & $<0,0001$ \\
\hline
\end{tabular}

* Foram excluídas desta análise as puérperas que foram admitidas em período expulsivo e as que não receberam medicação ou não lembravam se haviam recebido.

Nota: Para as subcategorias "informação sobre exames realizados - suficiente" e "informações sobre medicação recebida -

suficiente", o tamanho da amostra foi pequeno, considerando-se um erro de estimação de $10 \%$ e um grau de confiabilidade de $95 \%$.

O depoimento de algumas mulheres ilustra a importância que uma assistência cuidadosa e afetuosa tem para a satisfação com o parto, sendo feitas diversas sugestões para que os profissionais sejam mais atenciosos, pacientes, informativos, afetivos, "educados", e que não emitam opiniões pessoais sobre a vida e o comportamento das pacientes.

"A equipe foi carinhosa. Me trataram bem" (22 anos, terceiro parto). "O parto foi muito bom porque tive todo apoio da equipe. Foram eficientes" (29 anos, quinto parto). "Quando estava sentindo a dor e alguma enfermeira chegava perto eu me sentia mais segura. Não importava o que ela estivesse falando" (18 anos, primeiro parto). "Os médicos foram maravilhosos, não poderiam ter sido melhor. Me deram as informações que eu precisava. O médico deu orientação ainda no pré-parto. Tem que continuar assim. Achei bom demais. O desconforto não é tão importante como o conforto emocional. O resto você tira de letra. O médico te atender bem e você se sentir segura" (36 anos, segundo parto). "Acho que os médicos deveriam ser mais pacientes, atenciosos e pensarem mais no próximo, se colocarem no lugar do outro" (18 anos, primeiro parto). "Faltou um pouco de afe- to de alguns" (26 anos, segundo parto). "Os médicos devem ser mais pacientes, mais educados" (38 anos, oitavo parto). "Os profissionais não deveriam emitir suas opiniões sobre a vida pessoal das pacientes. Um dos profissionais me falou que eu não pensei na minha mãe na hora de fazer o bebê" (17 anos, primeiro parto).

\section{Discussão}

Alguns trabalhos que discutem a avaliação da satisfação das mulheres com a assistência ao parto apontam dificuldades para a realização desse tipo de estudo 15,16,18. Os pacientes, de modo geral, têm dificuldade em criticar o serviço de saúde e os profissionais que o atenderam, principalmente em situações de risco. No caso da assistência perinatal, essa dificuldade pode ser ainda maior, pois as mulheres tendem a se sentir aliviadas, agradecidas e com sentimentos positivos após o nascimento de uma criança saudável, compensando qualquer experiência negativa durante a assistência. Nos dias imediatamente após o parto, em especial, as mulheres podem hesitar em criticar a assistência recebida e os profissionais envolvidos, 
principalmente se elas ainda se encontram hospitalizadas.

Neste estudo, as entrevistas foram feitas ainda durante a internação, num momento muito próximo ao parto, por duas profissionais que já atuavam no serviço, fatores que, teoricamente, poderiam dificultar a avaliação da satisfação. Nessas circunstâncias, os resultados obtidos podem ser considerados conservadores e provavelmente subdimensionam as reais condições de insatisfação das puérperas.

Mesmo assim, verificamos insatisfação de parte das mulheres com seu parto, críticas relacionadas à atuação dos profissionais e sugestões apresentadas para a melhoria da assistência, o que nos leva a crer que as mulheres tiveram a possibilidade de expressar opiniões negativas em relação ao serviço. Avaliamos que o resultado encontrado de aproximadamente $33 \%$ das mulheres com algum grau de insatisfação - avaliação do parto como "nem bom, nem ruim", "ruim" e "muito ruim" - é expressivo, considerando-se que foram excluídos os resultados perinatais negativos (óbitos fetais e neonatais).

Ainda que esse valor possa estar subestimado, por um viés de mensuração, determinado pelos problemas mencionados anteriormente, os fatores identificados como associados a essa insatisfação são condizentes com os dados verificados na literatura sobre o tema.

Exceção feita em relação ao número de partos, cujo resultado encontrado de menor satisfação entre as multíparas, observado na faixa de avaliação "muito bom", contraria o que foi encontrado na bibliografia estudada 16. No estudo de Green, as primíparas estiveram menos satisfeitas com o parto, e os autores atribuíram esse achado ao fato de elas terem geralmente partos mais longos, mais difíceis e muitas vezes com mais intervenções médicas.

Mesmo reconhecendo que o número de primíparas entrevistadas neste estudo foi pequeno, consideramos pertinentes algumas considerações acerca da possível influência do contexto de vida das mulheres pesquisadas na determinação da satisfação com o parto. O estudo realizado por Green et al. 16 foi realizado na Inglaterra, país com melhores condições sociais e de acesso a serviços de saúde, inclusive para interrupção de uma gravidez não desejada. Nessas circunstâncias, é provável que fatores relacionados ao processo do parto em si, como a dor e as intervenções médicas, tenham maior influência na determinação da satisfação, justificando a menor satisfação das primíparas. Já num contexto como o nosso, em que as multíparas apresentavam maior percentual de gestações não planejadas e desejadas, menor acesso a serviços de pré-natal e menor apoio social e emocional durante a gravidez e o parto, os fatores sociais podem ter contribuído para uma menor satisfação na vivência desses eventos, superando aspectos obstétricos teoricamente mais favoráveis para as multíparas.

O mesmo estudo de Green et al. 16 demonstrou que fatores emocionais pré-natais parecem afetar os resultados psicológicos após o parto. Mulheres que ficam infelizes ao se descobrirem grávidas tendem a permanecer infelizes durante a gravidez e o parto, e isso influencia suas respostas pós-natais. Mulheres com poucas expectativas e muito ansiosas em relação à dor do parto também foram as que tiveram piores resultados emocionais.

Neste estudo, encontramos associação da variável "idéias negativas sobre o parto" com a menor satisfação com o parto. Da mesma forma, a variável "sentimentos negativos em relação à gravidez" apresentou associação inversa com a categoria de satisfação "muito bom". Não foi encontrada, no entanto, associação das variáveis "preocupação com o parto" e "informações sobre o parto" com a satisfação das mulheres. Em relação a esses pontos, o pequeno tamanho da nossa amostra aponta para a necessidade de novos estudos que possam melhor investigar esses fatores.

Das questões relacionadas à assistência ao trabalho de parto e ao parto, ressaltamos aquelas apontadas pelas mulheres como justificativa para uma maior satisfação, como um parto rápido, com pouca dor/sofrimento, sem complicações para si e seu bebê, com bom tratamento pela equipe e com a presença de acompanhante familiar.

Em estudo realizado no Canadá 18 , a intensidade da dor, a duração do trabalho de parto e a ocorrência de complicações também foram os fatores mais importantes para a satisfação das mulheres com a experiência do parto. Particularmente a presença do "resultado", que é o bebê, tem sido apontada em alguns estudos como um dos fatores intervenientes na avaliação da satisfação com o parto, levando a uma sistemática presença de altos graus de satisfação, tanto em relação à equipe, quanto em relação ao serviço (Riley, 1977, apud Reid 19).

O relacionamento da mulher com a equipe dos profissionais de saúde é tido como um dos fatores que mais afetam a memória das mulheres em relação à experiência do parto e do nascimento, tendo grande importância para sua satisfação 16. Mulheres valorizam conforto físico, suporte psicológico, cuidado personalizado, privacidade, além de um cuidado apropria- 
do fornecido por um número pequeno de profissionais 15 , que sejam responsivos às perguntas e que reconheçam as suas necessidades 12 .

$\mathrm{O}$ relato de violência percebido pelas mulheres durante o atendimento também foi verificado em outros estudos. D'Oliveira et al. 20 identificaram uma série de trabalhos realizados na última década que apontam para a ocorrência rotineira de violência nos serviços de atendimento ao parto e ao abortamento. As autoras focalizam a violência expressa sob quatro formas: (a) negligência; (b) violência verbal, incluindo tratamento grosseiro, ameaças, reprimendas, gritos e humilhação intencional; (c) violência física, considerada também como a não-utilização de medicação analgésica quando tecnicamente indicada, e (d) abuso sexual.

Esses autores assinalam que muitas mulheres descrevem a negligência como o aspecto mais estressante da sua experiência, pelo medo de danos à sua saúde e à de seu bebê, sendo interpretada como um sinal de que a equipe não se importa ou que não está atuando profissionalmente. Muitas vezes, embora a assistência esteja sendo prestada dentro dos limites do que se considera uma boa prática, a negligência é percebida pela falta de informação, suporte e compaixão, elementos que as mulheres consideram necessários para se sentirem bem cuidadas.

Santos \& Siebert ${ }^{8}$, em estudo realizado no Hospital Universitário de Santa Catarina, verificaram que alguns dos aspectos mais valorizados pelas mulheres durante o atendimento nessa maternidade foram a atenção imediata às suas necessidades, o bom humor, a dedicação e a preocupação da equipe. Em estudo nessa mesma instituição (Santos, 1998, apud Santos \& Siebert 8), algumas atitudes dos profissionais, como atenção, orientação, presença constante, uso de terminologias compreensíveis, estabelecimento de uma relação de segurança e confiança e a facilitação no entendimento do cuidado fornecido, foram importantes para a mulher que estava vivendo o processo do parto.

Em relação à presença do acompanhante, vários estudos internacionais demonstram que a presença de um(a) acompanhante familiar, em especial do parceiro, é um dos fatores que mais contribui para a satisfação das mulheres com a assistência recebida durante o parto 15,16,21. Neste estudo, o número de mulheres que atribuíram sua maior satisfação com o parto à presença do acompanhante foi relativamente pequeno $(12,4 \%)$. Como demonstrado anteriormente, fatores mais diretamente relacionados ao processo da parturição, como a sua duração, intensidade da dor/sofrimento e a relação com os profissionais que prestaram assistência, tiveram maior contribuição para a satisfação com o parto do que a presença do acompanhante.

Esse resultado, entretanto, não deve diminuir a importância dessa prática. Diversos trabalhos científicos demonstram os efeitos benéficos do suporte emocional no parto, como menor uso de medicação analgésica, menor uso de intervenções obstétricas (uso de fórceps, ocitócicos e parto cesariano) e melhores condições de vitalidade do recém-nato 11,12,22. Dessa forma, ao interferir positivamente nesses aspectos do processo da parturição, a presença do acompanhante pode estar contribuindo para a satisfação com o parto, mesmo que não esteja sendo referida pelas mulheres.

Devemos ressaltar também a elevada satisfação das mulheres com essa prática. Em estudo realizado na Maternidade Leila Diniz 13, demonstrou-se que mais de $95 \%$ das mulheres avaliaram a presença do acompanhante familiar durante a assistência ao trabalho de parto e ao parto como "boa" ou "muito boa", resultado observado mesmo entre puérperas insatisfeitas com atenção ao parto. As mulheres valorizaram o conforto físico e o suporte emocional proporcionados pelo acompanhante familiar e manifestaram o desejo de que essa prática fosse estendida a todas as maternidades 13 . Outras experiências nacionais também têm revelado a satisfação das mulheres com o suporte emocional no parto por mulheres leigas $9 \mathrm{e}$ por familiares 8 . A presença de acompanhante familiar durante a assistência ao trabalho de parto e ao parto é uma das práticas reconhecidas como benéficas pela OMS para atenção aos partos de baixo risco 10,11.

A maior satisfação com o parto encontrada neste estudo entre as mulheres com maior nível de informação durante a internação é condizente com o que foi encontrado na literatura consultada 15,16. O grau de informação, tanto durante a gravidez, como durante o trabalho de parto e parto, tem sido mostrado como fator de grande relevância para as mulheres, por possibilitar maior participação no processo decisório e aumentar sua percepção de estar no controle da situação, influenciando a satisfação com o parto.

O envolvimento no processo decisório/controle da situação tem sido apontado como uma das questões principais para a satisfação das mulheres com os serviços que atendem o parto 15. De modo geral, a questão do controle, tanto interno (relacionada ao próprio comportamento), quanto externo (relacionada ao ambiente, incluindo a equipe de saúde), é importante para as mulheres, seja para a vivência do parto, 
seja para os resultados psicológicos. Apesar de alguns aspectos negativos que podem estar relacionados à questão do controle, como maior ansiedade das mulheres e conflitos com a equipe de saúde, a revisão da literatura sobre o tema sugere que mulheres com mais controle, ou que se percebem com mais controle, têm experiências mais positivas do parto, maior nível de satisfação e menor depressão 16 .

Neste estudo, embora a questão do controle não tenha sido abordada, registramos duas razões de satisfação com o parto que nos remetem ao controle interno: uma mulher que referiu "ter conseguido ficar calma, me controlar e ter paciência”, e a outra que ficou satisfeita por "ter sido forte". Cabe ressaltar que a importância atribuída pelas mulheres à participação no processo decisório não apresenta variação com o nível sócio-econômico das mulheres 16,18,23.

Para finalizar, recomendamos a realização de outros estudos que avaliem a situação bra- sileira e aprofundem a discussão sobre a satisfação com o parto. Como o significado da parturição e da maternidade sofre importantes variações nos diversos contextos sócio-culturais, é importante conhecer as expectativas das mulheres brasileiras em relação ao parto para poder avaliar sua satisfação com esse evento, considerando as peculiaridades dos diferentes locais e características da assistência.

Identificar os componentes da satisfação das mulheres com a assistência ao parto é uma etapa fundamental para a organização de serviços voltados para as necessidades da clientela, visando à pretendida humanização da atenção ao parto e ao nascimento. Acreditamos que os resultados deste trabalho, apesar das limitações apontadas, podem ter contribuído para esse debate, delineando caminhos a serem seguidos e questões que precisam ser aprofundadas em pesquisas futuras.

\section{Resumo}

Este estudo tem por objetivo analisar os fatores que estiveram associados à satisfação das mulheres com a assistência ao parto normal na Maternidade Leila Diniz. Realizou-se um estudo com desenho transversal por meio de entrevista com puérperas de parto vaginal internadas no período de $1^{\circ}$ a 30 de março de 1999. Para averiguar o grau de satisfação, foram utilizadas: (a) uma escala para avaliação global do parto; (b) a descrição das razões alegadas pelas mulheres para essa avaliação $e$ (c) análise de fatores associados à satisfação com o parto. O Qui-quadrado para teste de tendência, com nível de significância de 5\%, foi utilizado para a análise dos resultados. Encontrou-se uma elevada satisfação com o parto (67\%), sendo os principais determinantes da satisfação a rapidez do parto, o bom tratamento da equipe, o pouco sofrimento, o bom estado da mãe e do bebê, bem como a presença do acompanhante familiar. Verificou-se também associação dessa satisfação com a informação fornecida durante a assistência ao trabalho de parto e ao parto, e com a percepção positiva dos profissionais que forneceram essa assistência.

Assistência Perinatal; Humanização do Parto; Satisfação do Usuário

\section{Colaboradores}

R. M. S. M. Domingues participou de todas as etapas, desde a coleta das informações até a redação final do artigo. E. M. Santos contribuiu na definição dos objetivos, método e na redação e revisão final. M. C. Leal colaborou na análise, discussão dos resultados e redação do artigo. 


\section{Referências}

1. Jordan B. Birth in four cultures - a crosscultural investigation of childbirth in yucatan, holland, sweden and the United States. 4th Ed. Prospect Heights: Waveland Press; 1993.

2. Helman CG. Cultura, saúde e doença. Porto Alegre: Artes Médicas; 1984.

3. Wagner M. Pursuing the Birth Machine. The search for appropriate birth tecnology. Australia: ACE Graphics; 1994.

4. Área Técnica de Saúde da Mulher. Parto, aborto e puerpério - assistência humanizada à mulher. Brasília: Secretaria de Políticas de Saúde, Ministério da Saúde; 2001.

5. Paciornik C. Análise perinatal de 11.100 partos de cócoras. In: Sabatino H, Dunn P, Caldeyro Barcia $\mathrm{R}$, organizadores. Parto humanizado - formas alternativas. Campinas: Editora Unicamp; 1992. p. 149-59.

6. Sabatino H, Vilarino J. Avaliação obstétrica de partos em posição de cócoras. In: Sabatino H, Dunn P, Caldeyro-Barcia R, organizadores. Parto humanizado - formas alternativas. Campinas: Editora Unicamp; 1992. p. 171-87.

7. Lima K. Maternidade Leila Diniz (1994-1996): nascimento de um novo profissional de saúde? [Dissertação de Mestrado]. Rio de Janeiro: Instituto Fernandes Figueira, Fundação Oswaldo Cruz; 1997.

8. Santos OMB, Siebert ERC. The humanization of birth experience at the University of Santa Catarina maternity hospital. Int J Gynaecol Obstet 2001; 75 Suppl 1:S73-9.

9. Leão MRC, Bastos MAR. "Tendo uma pessoa do lado a gente fica muito mais forte... a dor até diminui": Estudo etnográfico sobre parturientes acompanhadas por "doulas". Resumo de trabalhos da Conferência Internacional sobre Humanização do Parto e Nascimento; 2000 nov 2-4; Fortaleza, Brasil. Fortaleza: Jica - Aliança Luz; 2000.

10. Anonymous. Appropriate technology for birth. Lancet $1985 ; 2: 436-7$.

11. World Health Organization. Care in normal birth: a pratical guide. Genebra: World Health Organization; 1996.

12. Enkin M, Keirse MJNC, Neilson J, Duley CCLD, Hodnett E, Hofmeyr J. A guide to effective care in pregnancy and childbirth. New York: Oxford University Press; 2000.
13. Domingues RMSM. Acompanhantes familiares na assistência ao parto normal: a experiência da Maternidade Leila Diniz [Dissertação de Mestrado]. Rio de Janeiro: Escola Nacional de Saúde Pública, Fundação Oswaldo Cruz; 2002.

14. Ware JE, Hays RD, Methods for measuring patient satisfaction with specific medical encounters. Med Care 1988; 26:393-402.

15. Murray I, Wilcock A, Kobayashi L. Obstetrical patient satisfaction. J Health Care Mark 1996; 16:547.

16. Green J, Coupland V, Kitzinger J. Great expectations - a prospective study of women's expectations and experiences of childbirth. Cheshire: Books for Midwives Press; 1998.

17. Fleiss JL. Statistical methods for rates and proportions. New York: John Wiley \& Sons; 1981.

18. Séguin L, Therrien R, Champagne F, Larouche D. The components of women's satisfaction with maternity care. Birth 1989; 16:109-13.

19. Reid M. Non-medical aspects in the evaluation of prenatal care for women at low risk. In: Comission of the European Communities/Health Services research, editors. Perinatal care delivery systems: description and evaluation in european community countries. Series no 1 . Oxford: Oxford University Press; 1986. p. 77-89.

20. D'Oliveira AFPL, Diniz SG, Schraiber LB. Violence against women in health-care institutions: an emerging problem. Lancet 2002; 359:1681-5.

21. Smith M, Acheson L, Byrd J, Curtis P, Day T, Frank $\mathrm{S}$, et al. A critical review of labor and birth care. J Fam Pract 1991; 33:281-92.

22. Hodnett ED. Caregiver support for women during childbirth. (Cochrane Review) In: The Cochrane Library, Issue 1, 2002. Oxford: Update Software.

23. Kitzinger S. Birth and violence against women generating hypotheses from women's accounts of unhappiness after childbirth. In: Roberts H, editor. Women's health matters. London/New York: Routledge; 1993. p. 63-79.

Recebido em 08/Out/2002

Versão final reapresentada em 25/Jun/2003 Aprovado em 16/Set/2003 